\title{
Erratum to: Evaluating the short-term cost of low-level local air pollution: a life satisfaction approach
}

\author{
Christopher Barrington-Leigh ${ }^{1}$ - Fatemeh Behzadnejad ${ }^{2}$
}

Published online: 19 May 2016

(C) Society for Environmental Economics and Policy Studies and Springer Japan 2016

\section{Erratum to: Environ Econ Policy Stud DOI 10.1007/s10018-016-0152-7}

Unfortunately the acknowledgement section was not included in the original publication of the article.

The Acknowledgement is given in this Erratum.

The analysis presented in this paper was conducted at the McGill-Concordia Laboratory of the Quebec Inter-University Centre for Social Statistics which is part of the Canadian Research Data Centre Network (CRDCN), and funded by SSHRC, the CIHR, the CFI, Statistics Canada and the partner universities. The views expressed in this paper do not necessarily represent the CRDCN's or that of its partners'. Barrington-Leigh was supported by funding from the Social Science and Humanities Research Council of Canada and the Fonds Société et Culture de Québec.

The online version of the original article can be found under doi:10.1007/s10018-016-0152-7.

Christopher Barrington-Leigh cpbl@alum.mit.edu

1 McGill University, 1130 Pine Ave West, Montreal H3A 1A3, Canada

2 University of Liverpool Management School, Chatham Street, Liverpool L69 7ZH, UK 